\title{
A Study to assess the prevalence of Depression, Anxiety and Stress among Interns across the State of Maharashtra, India
}

\author{
Heena Merchant ${ }^{1}$, Ajita Nayak ${ }^{2}$, Alhad Mulkalwar ${ }^{3}$ \\ ${ }^{1}$ Assistant Professor, Department of Psychiatry, Seth G.S. Medical College and K.E.M. Hospital, \\ Mumbai. \\ ${ }^{2}$ Professor, Department of Psychiatry, Seth G.S. Medical College and K.E.M. Hospital, Mumbai. \\ ${ }^{3} 3^{\text {rd }}$ M.B.B.S. Student, Seth G.S. Medical College and K.E.M. Hospital, Mumbai. \\ Corresponding author: Alhad Mulkalwar \\ Email - alhad.mulkalwar@gmail.com
}

\begin{abstract}
Background and Objectives: The primary objective of this study was to determine the prevalence and severity of Depression, Anxiety and Stress among Interns in Medical Colleges and associated hospitals across Maharashtra and to identify the associated factors responsible for the same. The secondary objective was to correlate the prevalence of this psychological morbidity with their life style and the probable stressors experienced by them in the course of internship.

Methods: This study is an Observational, Cross-Sectional, Questionnaire Based Study which was conducted online with a sample of 362 interns. The data obtained was entered using Microsoft Excel 2013 and analyzed using SPSS 16.0 Software. The Pearson chi square correlation test was used to find out the association of various personal and life-style related factors with the levels of depression, anxiety and stress amongst the respondents.

Results: Amongst the total respondents, the prevalence of depression, anxiety and stress was found to be $59.70 \%, 63.03 \%$ and $38.79 \%$ respectively. Many factors specific to the course of internship were found to have a statistically significant correlation with high prevalence and severity of mental disturbances in the interns

Conclusion: There is a very high prevalence of depression, anxiety and stress among interns working in Maharashtra which needs to be effectively dealt with on an urgent basis. The strong association of the prevalence of psychological illnesses with many factors and stressors faced by them will help us highlight the contributory factors and suggest strategies to deal with them effectively at a personal, institutional and national level.
\end{abstract}

Keywords: Depression, anxiety, stress, medical interns.

(Paper received $-9^{\text {th }}$ March 2018, Peer review completed $-20^{\text {th }}$ March 2018)

(Accepted $-24^{\text {th }}$ March 2018)

\section{INTRODUCTION}

The importance of mental health has been recognized by World Health Organisation (WHO) since its origin, and is reflected by the definition of health in the WHO Constitution as "not merely the absence of disease or infirmity", but rather, "a state of complete physical, mental and social well-being" [1]. The World Health Organisation defines depression as a common mental disorder, characterized by sadness, loss of interest or pleasure, feelings of guilt or low self-worth, disturbed sleep or appetite, feelings of tiredness and poor concentration [2]. Stress is any uncomfortable "emotional experience accompanied by predictable biochemical, physiological and behavioural changes" [3]. Anxiety is an emotion characterized by feelings of tension, worried thoughts and physical changes like increased blood pressure, as defined by 
the American Psychological Association [4]. Today, mental health issues are a major public health concern due to their high prevalence rates, difficulties in detection, treatment and their tendency to become chronic. Also, a large proportion of students experiencing mental health problems are reluctant to open up due to the associated social stigma, considering it a sign of weakness and incompetence. As a result, many suffer in silence without seeking help [5].

Medical education has known to impose a significant psychological stress on undergraduate students [6]. Considerable degree and severity of psychological morbidity has been reported among medical students ranging from anxiety, stress, interpersonal problems, depression and suicidal ideation to psychiatric disorders [7-12] and they tend to have greater psychological distress than the general population [10]. The goal of medical education is to graduate knowledgeable, skilful and professional physicians and the current medical school curriculum has been designed accordingly. However, certain aspects of training may have unintended detrimental effects on students' mental health [13].

Of the many groups affected by such emotional states and disorders, doctors, especially the interns constitute an important class owing to the unique environment in which they work [14-15]. Factors like excessive working hours, sleep deprivation, and repeated exposure to emotionally charged situations play an important role in causing psychological morbidity in this group. In addition lack of job security, family and personal problems aggravate the stress [16]. With an extremely hectic schedule, it becomes difficult to find time for hobbies, exercise and relaxation. Lack of sound sleep, irregular and inappropriate food habits and unsatisfactory hostel stay further contribute to this [6]. The limited number of Postgraduate seats and the tough competition involved in order to secure one, poses a big dilemma in front of the interns; whether they should invest time in studying for entrance exams or work in the hospitals to gain clinical experience. The government's ever changing academic and medical policies, just add to the unending list of stressors in their lives. The recent rise in instances of violent attacks on health care professionals has also shown to have a negative impact on the interns, making them apprehensive and unable to perform their duties effectively and efficiently [17]. Although the interns have a very little clinical experience, they are expected to be proficient clinicians, educationists, researchers, and administrators.

Due to the nature of their profession, the mental well being of interns is not only of concern to them, but also is to the greater society served by them [16]. In India, a few studies have been done to find out the prevalence of stress, depression and anxiety in undergraduate medical students, but very few studies have been done to assess the emotional disturbances in interns; and even fewer to assess its causative or contributing factors. Hence, this study was planned to find the prevalence of stress, depression and anxiety and the factors associated with these emotional disorders in resident doctors working in medical colleges and associated hospitals across the state of Maharashtra.

\section{METHODOLOGY}

Study design: Observational, Cross-Sectional, Online Questionnaire Based Study

Duration of study: 2 months

Place of study: All medical colleges and affiliated hospitals across the state of Maharashtra Sample size and method of sampling

The total number of working interns in Maharashtra (Government and Private medical colleges and affiliated hospitals is around 6,245. With a Confidence Level of $95 \%$ we chose a sample size of $\mathbf{3 6 2}$ interns with a Confidence Interval of $5 \%$

\section{Inclusion criteria:}

Interns in medical colleges and affiliated hospitals across the state of Maharashtra

\section{Exclusion criteria:}

- Postgraduate medical students and Registered Medical Practitioners

- Students of Paramedical courses

- Any student not consenting to participate in the study

- Students with previously diagnosed depression or psychiatric ailments 


\section{Tools used}

1. Self Designed Questionnaire: A self-designed questionnaire to gather information about the socio-demographic and personal characteristics, general schedule, daily activities and life style of the respondents. The questions were designed after conducting a pilot study amongst a few students wherein they were asked about the factors which they feel to be directly or indirectly responsible for the high rate and degree of depression, anxiety and stress in medical students. The questionnaire includes Multiple Choice Questions, Yes/No type Questions, Likert Scale questions and Personal Opinion Questions. No question was mandatory for the respondent to answer and complete confidentiality was maintained. The questionnaire was validated by faculty members from the department of Psychiatry, Clinical Pharmacology and Pharmacology of the institute.

2. Depression Anxiety Stress Scale (DASS-21): DASS-21 is a previously validated and standardized 21-item questionnaire which includes three self-report scales designed to measure the negative emotional states of depression, anxiety and stress. Each of these three scales contains 14 items, which has been divided into subscales of 2-5 items with similar content. The Depression scale assesses dysphoria, devaluation of life, hopelessness, self-deprecation, lack of interest / involvement, anhedonia and inertia. The Anxiety scale assesses situational anxiety, skeletal muscle effects and subjective experience of anxious affect. The Stress scale is sensitive to levels of chronic non-specific arousal. It assesses difficulty relaxing, nervous arousal, and being easily upset/agitated, irritable/over-reactive and impatient. Respondents are asked to use 3-point severity/frequency scales to rate the extent to which they have experienced each state over the past week [18].

The study was conducted with the help of this online questionnaire in the form of a Google document for interns working in medical colleges and associated hospitals across Maharashtra. We emailed a copy of our survey questionnaire and the approval granted by the Institutional Ethics Committee of the institute along with a request letter to conduct the survey amongst the undergraduate medical students of the respective colleges to the Deans of all the medical colleges of Maharashtra. On receiving their permission, we dispatched the link of the online survey to the students of the concerned medical college using various social media platform. The students were able to access the questionnaire only after consenting to participate in the study after reading the Informed Consent Document. The first 362 responses were considered for further statistical analysis.

\section{STATISTICAL ANALYSIS}

The data obtained was entered using Microsoft Excel 2013 and analyzed using SPSS 16.0 Software. The Pearson chi square correlation test was used to find out the association of few of the personal factors with the levels of depression, anxiety and stress amongst the respondents.

\section{RESULTS}

Among the 362 responses, for statistical convenience, those falling within the subscale of Normal and Mild were considered as 'Not Depressed/Anxious/Stressed' while those falling under the subscale of Moderate, Severe and Very severe were considered as 'Depressed/Anxious/Stressed' (Table 2). Of the total respondents, the prevalence of depression, anxiety and stress was found to be $59.70 \%, 63.03 \%$ and $38.79 \%$ respectively. Table 3 depicts the correlation of depression, anxiety and stress and the personal habits of the respondents with the corresponding strength of association. The levels were found to be strongly associated with the duration of sleep which the students had; being significantly lower in students facing psychological issues. Another important finding of this study was the high prevalence and frequency of alcohol consumption and smoking in those facing depression, anxiety or any stressor in their life. 
Graph 1: Responses to survey questionnaire-1

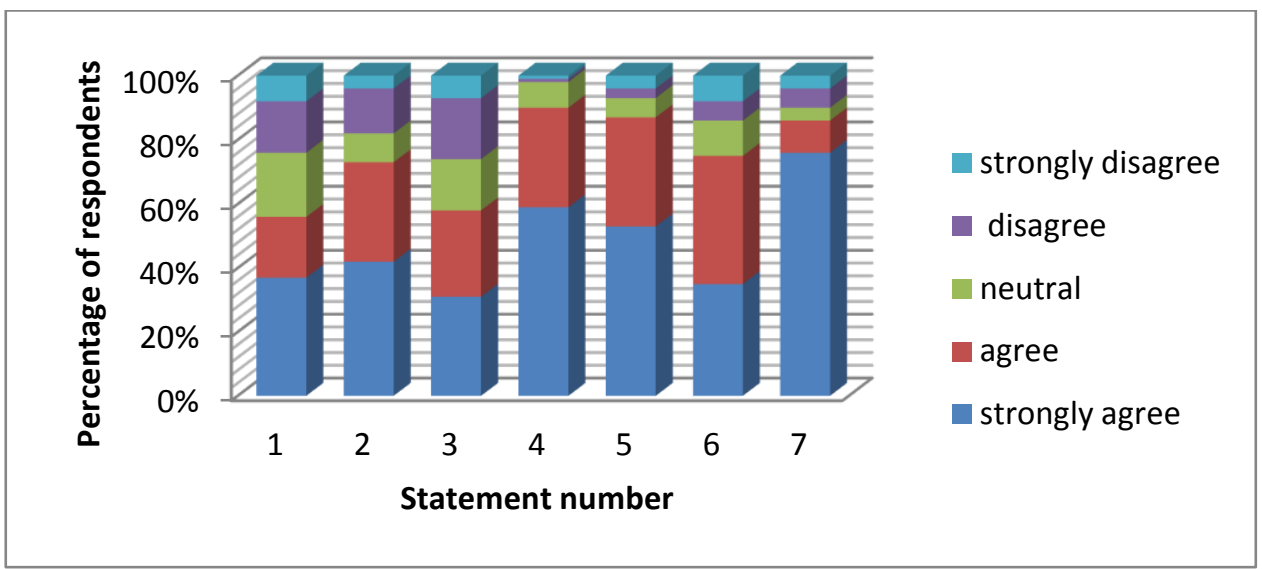

1. There is a discrepancy in the clinical experience depending on the unit you are posted in

2. Clinical knowledge gained in wards and questions asked in entrance exams are vastly different

3. The university should release a fixed uniform portion for all ward postings too

4. It is difficult to acquire the necessary clinical skills while preparing for PG entrance exams during internship

5. Separate coaching classes for PG entrance exams are necessary

6. There is a shortage of PG seats in the country

7. The Government's ever changing academic policies have a negative impact on you

Graph 2: Responses to survey questionnaire-2

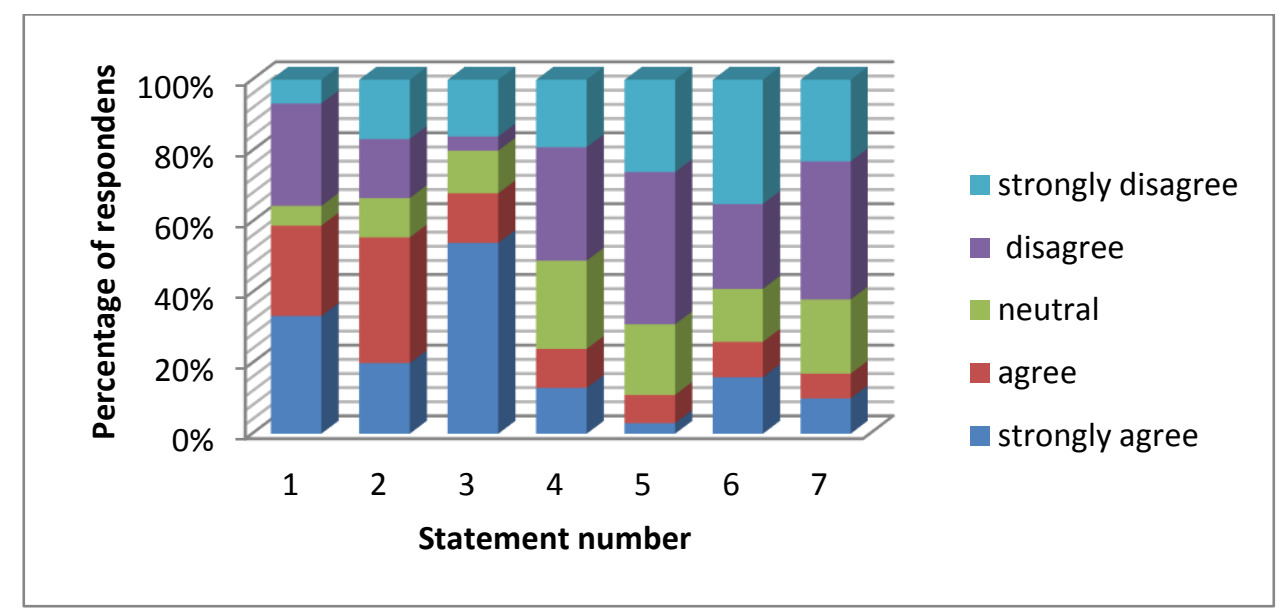

1. You often feel overworked

2. Your professional life affects your personal life

3. You are worried about extreme competition in the medical field

4. You are satisfied with your academic performance

5. You get time for pursuing hobbies

6. Your stipend as an intern is adequate

7. You get enough time to eat 
Table 1: Categories of depression, anxiety and stress in medical students according to DASS-21 scoring system

\begin{tabular}{|c|c|c|c|}
\hline Severity & Depression & Anxiety & Stress \\
\hline Normal & $0-4$ & $0-3$ & $0-7$ \\
\hline Mild & $5-6$ & $4-5$ & $8-9$ \\
\hline Moderate & $7-10$ & $6-7$ & $10-12$ \\
\hline Severe & $11-13$ & $8-9$ & $13-16$ \\
\hline Very severe & $14+$ & $10+$ & $17+$ \\
\hline
\end{tabular}

Table 2: Severity distribution of DASS scores among surveyed interns $(\mathrm{n}=362)$

\begin{tabular}{|c|c|c|c|c|c|}
\hline Subscale & Normal & Mild & Moderate & Severe & Extremely severe \\
\hline Depression & 73 & 73 & 115 & 71 & 30 \\
\hline Anxiety & 51 & 83 & 78 & 100 & 50 \\
\hline Stress & 120 & 102 & 58 & 67 & 15 \\
\hline
\end{tabular}

\section{DISCUSSION}

This study has served to fortify the general impression that there is a considerable amount of psychological morbidity amongst interns across medical colleges and associated hospitals. The results showed higher levels of morbidity in interns as compared to similar studies conducted in the past in India [19]. The interns are torn between preparing for entrance examinations to secure a respectable post-graduate seat in a good medical college and gaining clinical exposure to become better, more competent doctors. The current structure of medical education could be modified by taking this aspect into consideration. There are a very limited number of Post-graduate seats in the country and hence the ratio of aspirants to postgraduate seats becomes very high. Also, $71 \%$ of the respondents claimed that the questions asked in these entrance examinations differ significantly from the knowledge gained in wards while working as interns. Hence there is definitely a need for separate coaching classes to prepare for the exams, which simply adds to their burden. Moreover, $54 \%$ of the respondents also claimed that they experienced a discrepancy in the clinical experience depending on the unit they were posted in during their internship, to counter which $56 \%$ of the respondents were of the opinion that the university should release a fixed, uniform syllabus for all the clinical postings too. The frequently changing Government policies have also shown to have a negative impact, leaving interns uncertain and insecure about their future. The recent rise in the instances of violent attacks on doctors by patients' relatives has also shown to deter them from working freely, efficiently and fearlessly.

Other similar studies have documented this trend as well [20]. Stricter laws and their efficient implementation regarding the security of heath care professionals in hospitals such as limiting the number of relatives accompanying a patient may help tackle this issue. These are just few of the many factors which contribute to such a high prevalence of psychological morbidity amongst the interns of the state of Maharashtra. This definitely has a huge impact on the mental and physical well-being of the budding doctors. The long working hours leaves them overworked and fatigued. There was also a statistically significant association between the duration of sleep and stress and depression levels among the respondents. The tiring night shifts disrupt normal physiological eating and sleeping cycles and the circadian rhythm of students. The indulgence in smoking cigarettes and alcoholism has been reported with a greater frequency and intensity in medical students [21]. Our study has found this lifestyle of students to be significantly associated with the depression and stress levels of the surveyed interns. Many interns may resort to such behaviour to find a temporary escape from their stressful lives, using it as a coping mechanism. Majority of the interns also felt that their stipend was inadequate and should be increased. All these factors may contribute to the increasing morbidity amongst interns in one way or the other.

Limitations: The findings of this study are based on self reported information provided by students and some potential for reporting bias may have occurred because of student's interpretation of the questions or 
simply because of inaccuracies of responses or desire to report their emotions in a certain way. As the survey was conducted online, it may not have reached to all the students of the state and its access could have been limited by the use of electronic social media platforms.

Table 3 - Depression, anxiety and stress scores based on various lifestyle factors in medical interns

\begin{tabular}{|c|c|c|c|c|c|c|c|c|c|c|c|}
\hline \multirow[t]{2}{*}{ Category } & \multirow[t]{2}{*}{ Option } & \multirow{2}{*}{$\begin{array}{c}\text { Total } \\
\text { number of } \\
\text { respondents }\end{array}$} & \multicolumn{2}{|c|}{ Depression } & \multirow[t]{2}{*}{$\mathrm{p}$ value } & \multicolumn{2}{|c|}{ Anxiety } & \multirow[t]{2}{*}{$p$ value } & \multicolumn{2}{|c|}{ Stress } & \multirow[t]{2}{*}{$\mathrm{p}$ value } \\
\hline & & & Yes & No & & Yes & No & & Yes & No & \\
\hline \multirow{4}{*}{$\begin{array}{c}\text { Alcohol } \\
\text { intake }\end{array}$} & Never & 96 & 30 & 66 & \multirow[t]{4}{*}{$<0.001^{*}$} & 22 & 74 & \multirow[t]{4}{*}{$<0.001^{*}$} & 28 & 68 & \multirow[t]{4}{*}{$0.003^{*}$} \\
\hline & Rarely & 184 & 61 & 123 & & 62 & 122 & & 63 & 121 & \\
\hline & Sometimes & 68 & 42 & 26 & & 39 & 29 & & 20 & 48 & \\
\hline & Often & 14 & 13 & 1 & & 11 & 3 & & 11 & 3 & \\
\hline \multirow{4}{*}{$\begin{array}{l}\text { Cigarette } \\
\text { smoking }\end{array}$} & Never & 265 & 103 & 262 & \multirow[t]{4}{*}{$0.006^{*}$} & 94 & 171 & \multirow[t]{4}{*}{0.672} & 80 & 185 & \multirow[t]{4}{*}{$0.007^{*}$} \\
\hline & Rarely & 61 & 23 & 38 & & 26 & 35 & & 23 & 38 & \\
\hline & Sometimes & 29 & 16 & 13 & & 12 & 17 & & 13 & 16 & \\
\hline & Often & 07 & 04 & 03 & & 02 & 05 & & 6 & 1 & \\
\hline \multirow{3}{*}{$\begin{array}{l}\text { Duration } \\
\text { of sleep in } \\
24 \text { hours }\end{array}$} & $<4$ hours & 26 & 19 & 7 & \multirow[t]{3}{*}{$<0.001^{*}$} & 16 & 10 & \multirow[t]{3}{*}{$0.017^{*}$} & 21 & 05 & \multirow[t]{3}{*}{$<0.001^{*}$} \\
\hline & $4-6$ hours & 263 & 109 & 154 & & 89 & 174 & & 85 & 178 & \\
\hline & 6 hours & 73 & 18 & 216 & & 29 & 44 & & 16 & 57 & \\
\hline
\end{tabular}

\section{CONCLUSION}

There is a very high prevalence of depression, anxiety and stress among interns working in Maharashtra which needs to be effectively dealt with on an urgent basis. The strong association of the prevalence of psychological illnesses with many factors and stressors faced by them will help us highlight the contributory factors and suggest strategies to deal with them effectively at a personal, institutional and national level.

\section{REFERENCES}

1. World Health Organisation: Mental Health: New Understanding, New Hope. The World Health Report. World Health Organization. 200[1]. Available at http://www.who.int/whr/200[1]/en/10.03.2003

2. World Health Organisation, regional office for Europe, official web page: http://www.euro.who.int/en/health-topics/noncommunicablediseases/pages/news/news/2012/10/depression-in-europe/depression-definition

3. Baum A. Stress, Intrusive Imagery, and Chronic Distress. Health Psychology 1990;6:653-75.

4. Kazdin AE. Encyclopedia of Psychology. Cambridge University Press: Cambridge : UK ; 2000.

5. Schwenk T, Davis L, Wimsatt L. Depression, Stigma, and Suicidal Ideation in Medical Students. JAMA. 2010;304(11):1181-5.

6. Mosley TH, Jr, Perrin SG, Neral SM, Dubbert PM, Grothues CA, Pinto BM. Stress, coping, and well-being among third year medical students. Academic Medicine 1994;69:765-7.

7. Aktekin M, Karaman T, Senol YY, Erdem S, Erengin H, Akaydin M. Anxiety, depression and stressful life events among medical students: a prospective study in Antalya, Turkey. Medical Education 2001;35:12-7.

8. Chandavarkar U, Azam A, Mathews CA. Anxiety symptoms and perceived performance in medical students. Depress Anxiety 2007;24:103-11.

9. Eller T, Aluoja A, Vasar V, Veldi M. Symptoms of anxiety and depression in Estonian medical students with sleep problems. Depress Anxiety 2006;23:250-6. 
10. Dyrbye LN, Thomas MR, Shanafelt TD, Sreeramareddy CT. Perceived stress, sources and severity of stress among medical undergraduates in a Pakistani Medical School. BMC Med Educ 2006;81:354-73.

11. Shah M, Hassan S, Malik S, Sreeramareddy CT. Perceived stress, sources and severity of stress among medical undergraduates in a Pakistani Medical School. BMC Med Educ 2010;10:2.

12. Bayram N, Bilgel N. The prevalence and socio-demographic correlations of depression, anxiety and stress among a group of university students. Soc Psychiatry Psychiatr Epidemiol 2008;43:667-72.

13. Afsar N Kulsoom B. Stress, anxiety, and depression among medical students in a multiethnic setting. Neuropsychiatr Disease Treat 2015; 1713

14. Grunfeld E, Whelam TZ, Zitzelsberger L, Willioam AK, Manteants B, Evans WK. Cancer care workers in Ontario: Prevalence of burnout job stress and job satisfaction. Can Med Assoc J 2002;163:166-9.

15. Gundersen L. Physician burnout. Ann Intern Med 2001;135:145-8.

16. Demir F, Pýnar AY, ErbasM, Özdil M, Yapar E. The Prevalence of depression and its associated factors among resident doctors working in a training hospital in Istanbul. Turk J Psychiatry 2007;18:31-7.

17. Bolanowski W. Anxiety about professional future amongst young doctors. Int J Occup Med Environ Health 2005;18(4):367-74.

18. Lovibond SH, Lovibond Pf. Manual for the Depression anxiety Stress Scales. (2 ${ }^{\text {nd }}$ Ed) Sydney, Psychology Foundation;1995.

19. Deshpande JB, Phalke DB, Kalakoti P, Qutub D, Agrawal V. Stress Levels and Depression amongst Interns and Resident Doctors Working in a Tertiary Care Teaching Hospital in Rural Area. Int J Health Rehabil Sci 2013;2(1):44-9.

20. Elston MA, Gabe J, Denney D, Lee R, O'Beirne M. Violence against doctors: a medical(ised) problem? The case of National Health Service general practitioners; Sociol Health Illness 2002;24(5):575-98.

21. Lipp M, Tinklenberg J, Benson S, Melges F, Taintor Z, Peterson M. Medical Student Use of Marijuana, Alcohol, and Cigarettes: A Study of Four Schools. Int J Addictions Pages 2009;7:141-52.

$* * * * * * * * * * * * * * * * * * * * * * * * * * * * * * * * * * * *$

Acknowledgements - Nil

Conflict of Interest - Nil

Funding - Nil 